\section{Augmented Reality and Mobile GIS as Tools for Teaching Data- collection in the Context of Forest Inventories}

Gl_Forum 2019, Issue 2

Page: 129 - 143

Full Paper

Corresponding Author:

jan-peter.mund@hnee.de

DOI: 10.1553/giscience2019_02_s129

Jan-Peter Mund' and Susanne Müller²

'Eberswalde University for Sustainable Development, Germany

2Freelance author

\begin{abstract}
Innovative and disruptive technological innovations trigger educational advances. Novel sensor-based distance and height measurement tools or wearable augmented realty (AR) devices and cameras have recently been introduced into several University curricula focusing on the environmental sector. Consumer gadgets and mobile GIS support students during self-organized fieldwork by displaying collected data in an immersive AR.

This paper summarizes the authors' experiences in implementing a module re-design integrating a new didactical approach to teaching empirical data collection for forest inventories with the use of AR tools and mobile data-collection methods. The new module combines blended and mobile learning and state-of-the-art IT in order to address future professional needs of the forestry sector. The piloting of the module from 2016 to 2018 demonstrated the potential for the forestry sector of mobile learning that uses geospatial information and AR technologies.
\end{abstract}

\title{
Keywords:
}

GIS, Forest inventories, Augmented Reality, Mobile Learning

\section{Introduction}

During the last decade, geo-information techniques, location-based services (LBS) and augmented reality (AR) have advanced from experimental science-based innovations to accepted ready-made consumer electronics products (Rathmell, 2018). Thanks to novel geospatial, surveying and environmental assessment techniques, scientists are increasingly able to record the dynamics of the environment using modern, mobile digital surveying and data collection equipment (MaKinster et al. 2014).

Teaching the skills required for monitoring environmental parameters using geospatial aspects of LBS and AR has become essential in higher education curricula in the fields of forestry and ecosystem management (Morgenroth \& Visser, 2013). Teaching empirical data collection for the purposes of forest inventories specifically offers an intrinsically complex topic for several 
reasons: the sector sees less innovation due to long forestry production cycles and lasting product characteristics; empirical data in forestry is often still generated manually (Aufnahmeanweisung Bundeswaldinventur, Riedel et al., 2017); attitudes towards digital working methods and devices differ among forestry students (Adams et al., 2013).

This paper presents the design and piloting of a new higher education module that integrates mobile geo-information and computing techniques, features of $\mathrm{AR}$, and various learning approaches to enhance students' understanding of the principles of database management and the learning of up-to-date environmental data-collection methods in a realistic forest inventory application.

\section{The new module: content and sequence}

The higher education module discussed here teaches principles of empirical data collection and GIS for forest inventories and environmental monitoring. It targets BSc students who are either studying for a forestry degree or are on an ecosystem management programme. The main objective of this second-semester module is 'to enable students to independently carry out data collection, data management, analysis and visualization of forest inventory related spatial data in individual GIS projects' (HNEE, IFEM Curriculum; effective from WS 2015/16).

The motivation for re-designing the module was to increase students' operational autonomy and responsibility for the collection of empirical environmental and GIS data in forest stands by enabling mobile, in-context learning in inventory plots. The new approach introduces upto-date spatial data collection methods for a realistic forest inventory, merging mobile geoinformation techniques with features of $\mathrm{AR}$ and other e-learning methods. The module is aligned with typical industry job requirements and settings, creating significant added value for students, preparing them for careers connected to geo-spatial analysis.

The two course modules taught at the Eberswalde University for sustainable Development regularly draw a heterogeneous set of students, some with a strong interest in computer science and GIS, others with a strong dislike for technology. Students come from international or German federal state backgrounds. Their digital literacies levels vary widely. Here, digital literacy is understood in a very broad sense, as a capacity to continuously adjust, comprehend and utilize innovations in information technology (Koltay, 2011).

In order to be able to apply individually the data collection methods taught in the module, students need to master geo-spatial concepts, including spatial location, 2D and 3D data hierarchy, buffer and clipping tools, as well as raster and vector principles. They also need to understand how to combine forest mensuration techniques with spatial data acquisition and GIS tools for the creation of forest inventories, as well as how to solve problems using geospatial analytics and GIS software.

The learning process of the new module is sequenced in three phases, which include e-learning and elements of self-directed learning: 1. Information and Transfer; 2. Application; 3. Securing results. (See Figure 1.) 


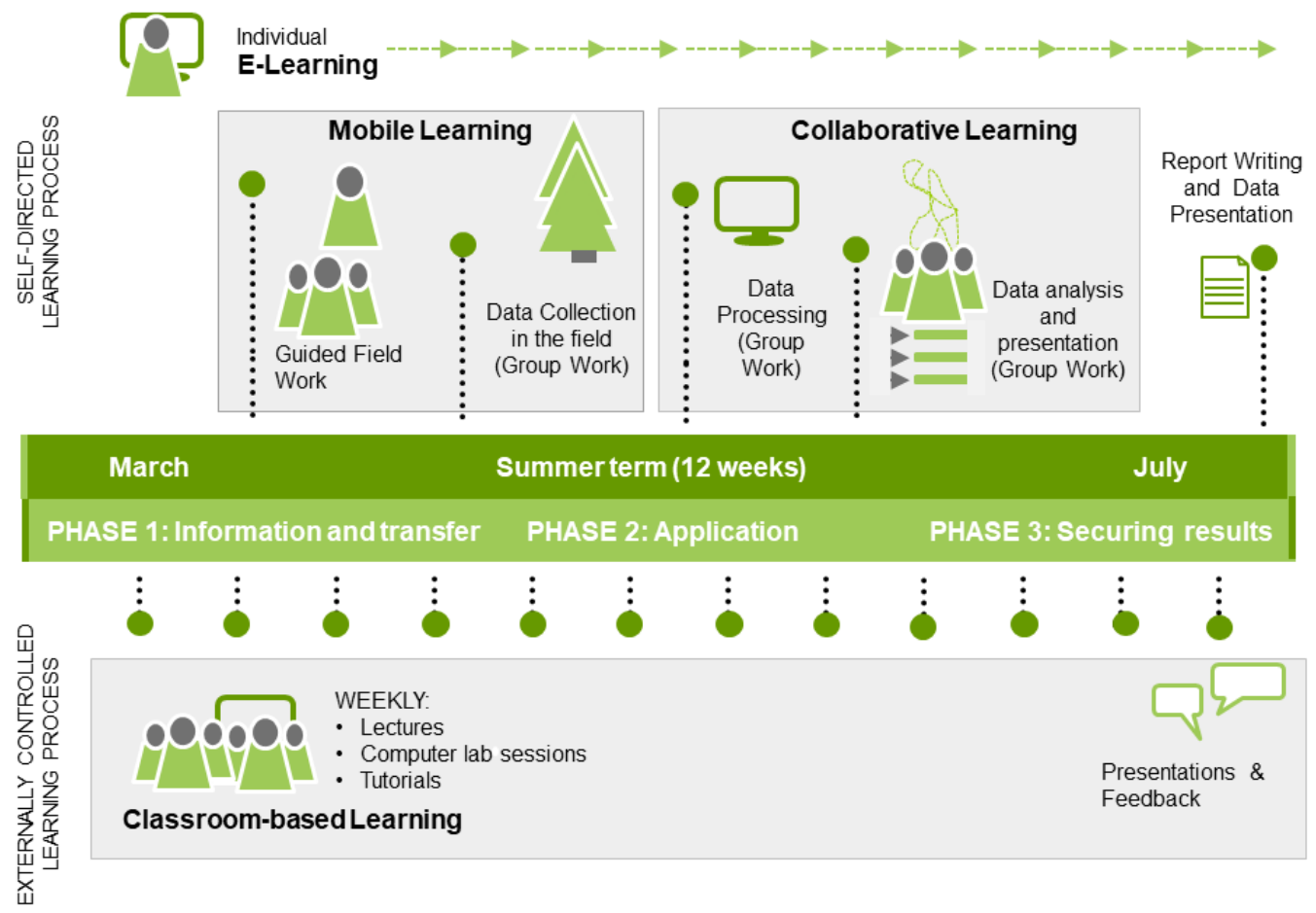

Figure 1: Sequence of the learning architecture

\subsection{Phase One: Information and Transfer}

During the introductory phase, short lectures and on-site presentations provide necessary theoretical information and methodological expertise.

Across 12 weeks of the summer term, the learning sessions deal with typical GIS principles of vector- and raster-based geospatial information, coordinate and reference systems, the combination of raster- and vector-based geospatial information, topical attribute data, calculating and converting polar to world coordinates, visualization and thematic cartography. The lecture topics are connected to an e-learning portfolio in order to facilitate flipped classroom methods and preparatory learning tasks. In addition, reading material and digital exercises enable self-directed learning.

All resources and learning materials can be accessed by the students at any time in an e-learning classroom linked to the university's network. The e-learning materials point to further online training opportunities, recommending particular internet tutorials and online video resources. Each lecture is followed by a practical computer lab session where students process geospatial data recently collected for their individual inventory into an ESRI online database which is part of the HNEE ESRI online repository. Students who prefer personal guidance rather than self-guided online tutorials have the opportunity to work with the lecturer or tutor to learn 
how to use GIS for spatial analysis to solve a problem similar to the ones they will encounter on their individual research plots. In the lab sessions, students are also able to discuss questions that arise in the self-directed learning phases.

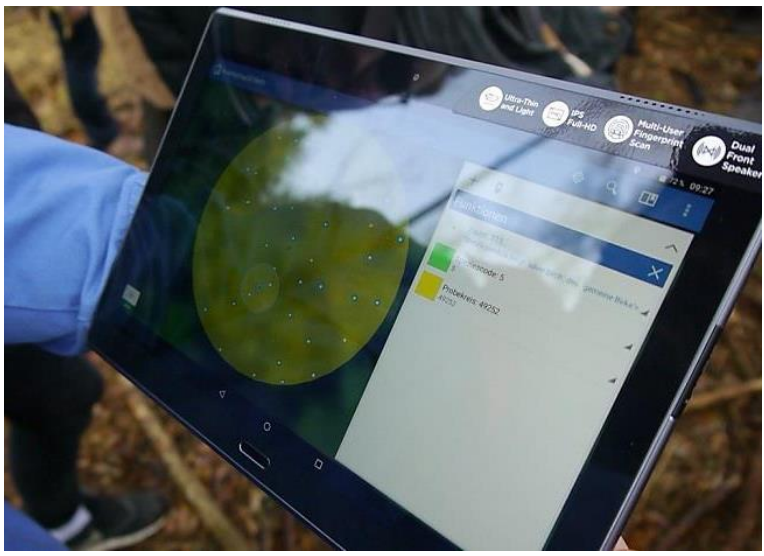

Figure 2: Mobile computing and realtime entry of forest inventory data during student fieldwork with ESRI ARC GIS Collector App

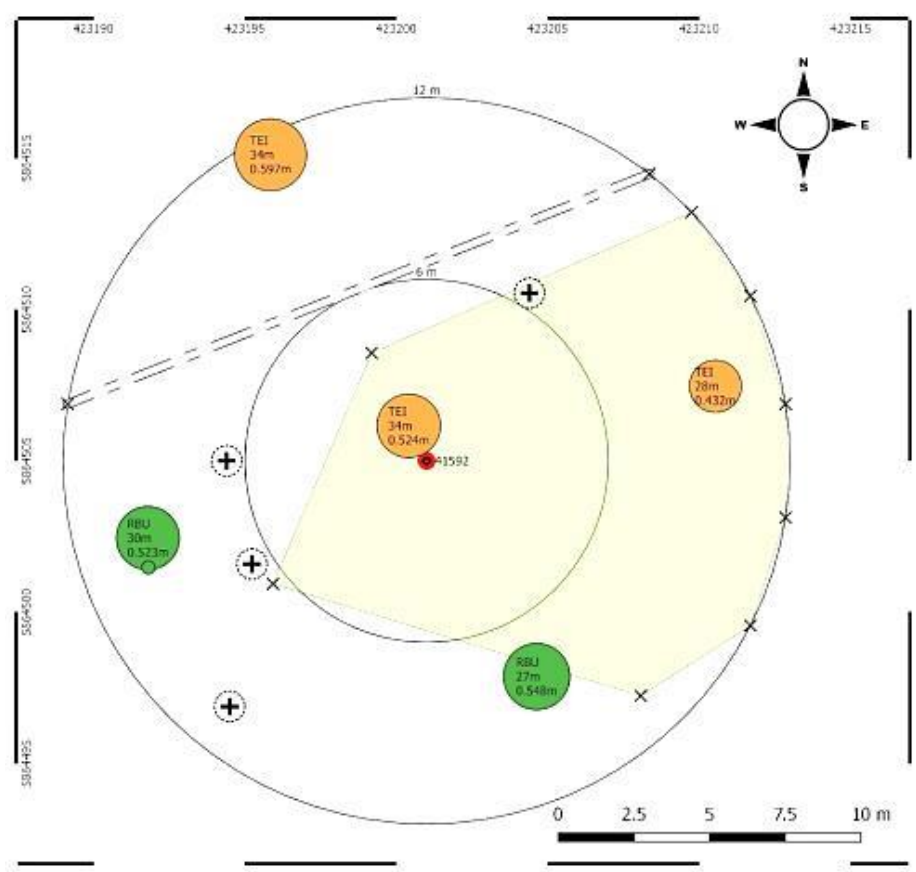

\section{Inventory Plot} 41592

Office of hicad forester; Eberswalde District: Oderberg
Devision: 192

Hot coordinates: $33 \mathrm{~N} 4232015864505$ Legend

Standing trees (bhd +2)

$\square$ European beexh

$\square$ Sessile oak

(t) Dead troes

Degivenation

$\longrightarrow$ Forest track

- Center picant Coordinate System:
ETRS99 / UTM 20ne 33A
frotectian: Universal Transverse Mercator Ellipsoid: GRS1800 (JUUK, 1800) Units: Meter created with: [Qgis]2:14.1-Ese lakob Wenert, Bruno Gammel Created $x$ :

Figure 3: Example of a circular forest inventory plot in the Eberswalde region, Germany, using a projected geo-reference system with auxiliary spatial and attribute information

Equipped with prior knowledge, students more easily comprehend particular forest inventory concepts and increase their GIS application competence (Clark et al. 2007). 


\subsection{Phase Two: Application}

In phase two, students apply the methods they have learnt in an actual forest plot. The authors intentionally chose an inverted classroom setting, 'swapping phases of knowledge acquisition and application' (Lambach et al., 2017, p. 554). During the first half of the 2nd term, in parallel to the classroom sessions, students form working groups for field data collection exercises, and guided practical fields days introduce students to their assignment. In groups of four, students work together on two circular forest inventory plots $(\mathrm{r}=12 \mathrm{~m})$ to collect empirical data (see Figure 3) following the principles of the federal state forest inventory guidelines. They need to navigate solo to the inventory plots and survey the assigned area. Additionally, students assess typical biological parameters such as species names, soil type and climatic conditions in their forest stands. They also differentiate between growth and yield functions in order to predict productivity (number of cubic metres harvested) and enter all collected data into a forest inventory training database, including inventory descriptions, stratification and auxiliary data.

During their fieldwork, immersive information or AR (Figure 4) provides students with digital spatial data attribute information and metadata for individual trees (e.g. physiological tree parameters) and other auxiliary information. The immersive information in the AR places the existing datasets in their original contexts. Multiple datasets can be presented and analysed simultaneously. Thus the AR supports mobile learning on the plot. Additionally, real-time AR data presentation and standardized data entry forms reduce individual data-entry errors as students compare their data live in the field.

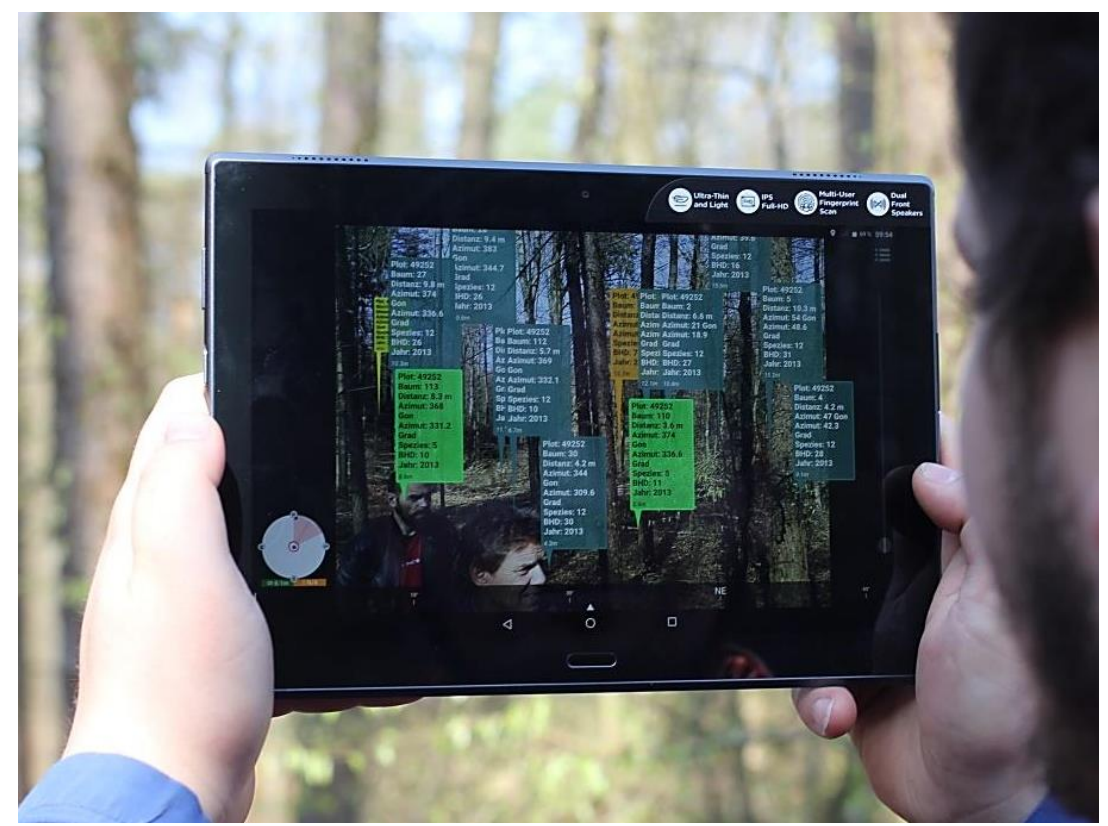

Figure 4: Screenshot of the immersive information (AR) displayed offline at each inventory plot. 
The learning process for data management continues with a comprehensive data quality assessment, followed by modification or correction of attributes if necessary. Updated spatial forest inventory information is now ready for further analysis of forest growth parameters, for being superimposed on background information for presentation (Figure 3), or for designing meaningful thematic maps.

\subsection{Phase Three: Securing results}

At the end of the learning process, the processed data is saved in the inventory database where it updates the existing attribute dataset with new data, thus expanding the existing AR for future use. The final examination part of the module consists of a presentation of the group assignment. Student groups need to discuss and present the analysis and visualization of the self-collected data to their peers, processing the collected data, producing overview maps, and comparing current data to previous datasets. A written report and a digital file with the collected and processed data need to be handed in for students to be credited for the module.

\section{The learning architecture of the module}

This new module employs parallel blended learning settings, where blended learning is understood as the linking of online and offline learning and teaching resources (Kopp et al. 2016). The module comprises:

- Classroom-based lectures and computer lab seminars

- Online e-learning, flipped classroom and video tutorials

- Individual and guided practical fieldwork at students' research plots.

The blended learning design combines classroom formats with online self-learning phases; mobile learning and independently organized project work in groups (see Figure 2). Mobile learning here is understood as an extension of e-learning (cf. de Witt and Sieber, 2013, p. 14). In contrast to e-learning, mobile learning is not necessarily online, but refers to learning processes that use mobile devices such as tablets on location. The introduction of mobile learning allows in-context learning on the forestry inventory plots and establishes a direct link between abstract learning and both concrete use cases and the relevant physical environments (Seipold, 2013).

Mobile and e-learning options serve as supports to compensate for differing or limited prior knowledge and divergent working methods in heterogeneous student groups. In this case, elearning ensures familiarization with, and practical use of, software and digital measuring devices before classroom teaching. By sequencing the materials and offering different learning methods, the module reaches out to a diverse set of learners and their needs. By combining face-to-face formats, digital self-study and self-organized group work, very different approaches were integrated to foster students' responsibility and reliability. Collaborative procedures and production processes for data collection and analysis strengthened students' logical thinking and collaboration between them. Further benefits for students included the promotion of transfer and decision-making skills. Mobile learning opened up a wider scope of action for students and gave them control in the learning context, including deciding when 
and where to study. The mixture of online and off-line teaching allows individualized, adaptive learning, with the ability to tailor learning speed and intensity to individual needs. Linking different learning approaches and teaching formats encourages and motivates students through activating learning and independent working methods (Goldstein \& Alibrandi, 2013).

The student assignment is designed according to problem-based learning (PBL) principles. The authors understand PBL in Moallem et al.'s (2019) sense, as offering an instructional method that focuses on problems as drivers of the learning process. PBL is considered an effective format and is popular for introducing geospatial applications and methods in particular (Howarth and Sinton, 2011). In their online work, students independently develop a digital data model for the acquisition of typical forest inventory and geospatial data. This approach enables students to independently recognize the need for a structured and organized data model which they then implement independently into their own learning environment. Dealing with the attribute parameters, digital processing, technical limitations and dangers of geospatial data is learnt using real examples, so that the students can transfer this experience into their future professions. Mobile visualization such as AR simulates collected data in the context of their occurrence (Veas et al., 2013). The idea of including an AR layer as learning material was triggered by research which found that using AR technology increases students' level of interest and/or engagement (Goff et al., 2018; Balog and Pribeanu, 2010; Dunleavy and Dede, 2014).

\section{Skills and intended learning outcomes}

The focus of the module rests more on linking the practical application of digital methodological skills with theoretical foundations of spatial data than on imparting subjectspecific and theoretical knowledge. The module has four general learning objectives (illustrated in Figure 5): to transfer factual and conceptual knowledge about various technologies and their functions; to build the capability of using and troubleshooting selected technology; to enhance critical thinking and decision making; to foster problem-solving skills, and soft skills such as group work and conflict resolution.

The intended learning outcomes that relate specifically to geospatial technologies are:

- Students are able to capture and organize spatial data using GIS and software.

- Students use AR and existing data infrastructures to compare spatial and attribute data.

- Students master basic GIS operations, including simple 2D mapping tasks, and become acquainted with selected software types (see Figure 4).

- Students independently carry out data collection, and perform simple spatial analysis and visualization of spatial data using ARC-GIS or Q-GIS.

- Students understand map projections and are able to use cartographic and analytical methods.

- Students relate environmental attribute data to geospatial data of individual trees and visualize them using digital presentation methods (see Figure 3). 


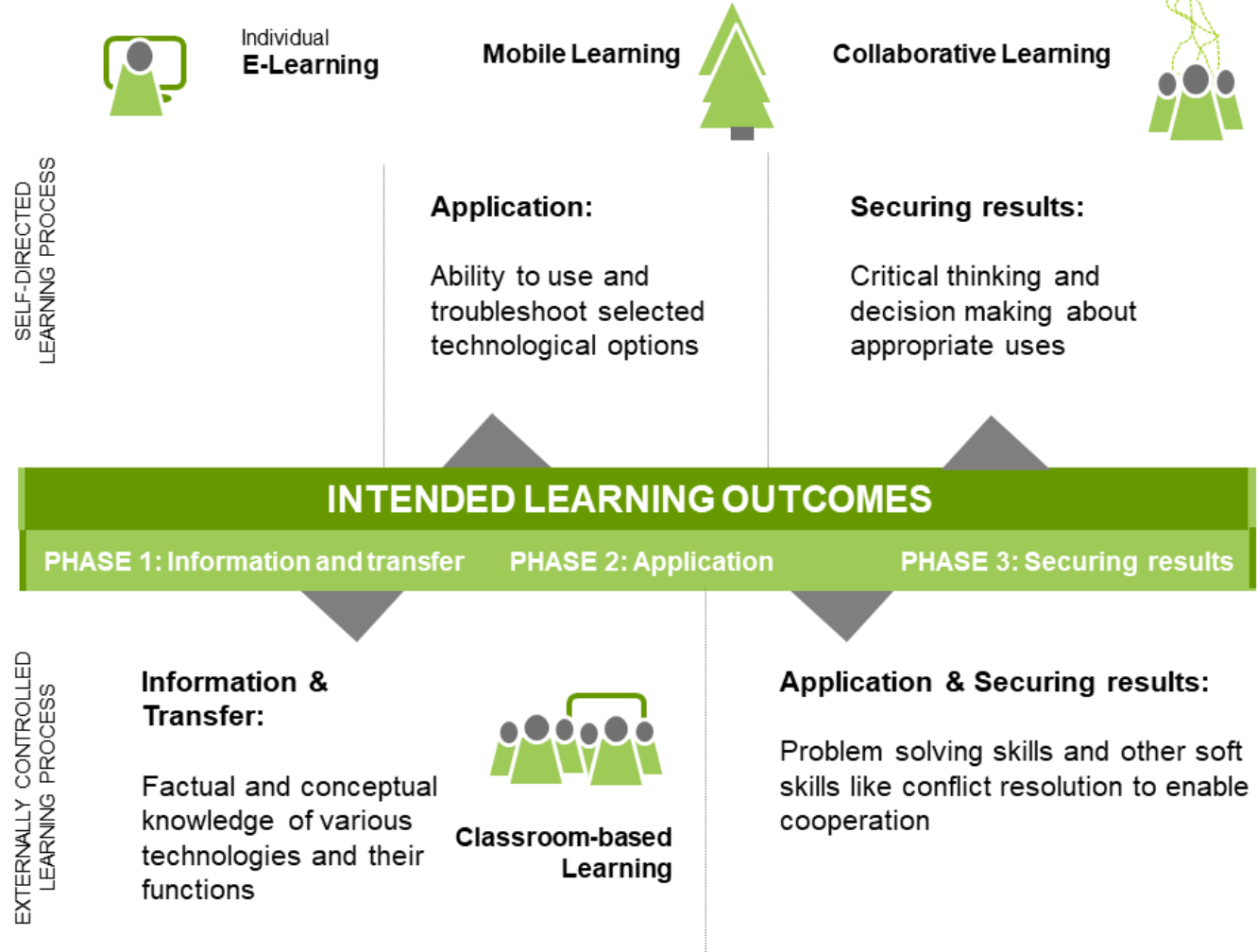

Figure 5: Intended Learning outcomes according to the sequence of the module

\section{$5 \quad$ Technical pre-conditions}

During practical field days, students make use of consumer tablets, mobile GIS applications, and AR software that visualizes data collected previously in the inventory plots. As the federal state forest administration in Brandenburg does not use a comprehensive forestry-oriented geo-data model, a database had to be introduced. This is similar to topographical data models like ATKIS (general topographical cadastral information system) or 'city gml' (Open Geospatial Consortium, ISO TC211). In 2012, a joint forest inventory training database was set up by the federal state forest service (LFE-LFB Brandenburg) and Eberswalde University for Sustainable Development that consists of approximately 160 separate inventory plots with ancillary attribute data for each inventoried tree (see Figures 2 and 6). Since then, all plots have been registered in an ESRI ArcGIS geospatial database and inventoried twice, by different student groups. Structured and parametrized attribute data for each plot are available (as seen in Figure 4) and support the permanent monitoring of environmental changes or yield growth of timber stock (ESRI Canada 2017). 

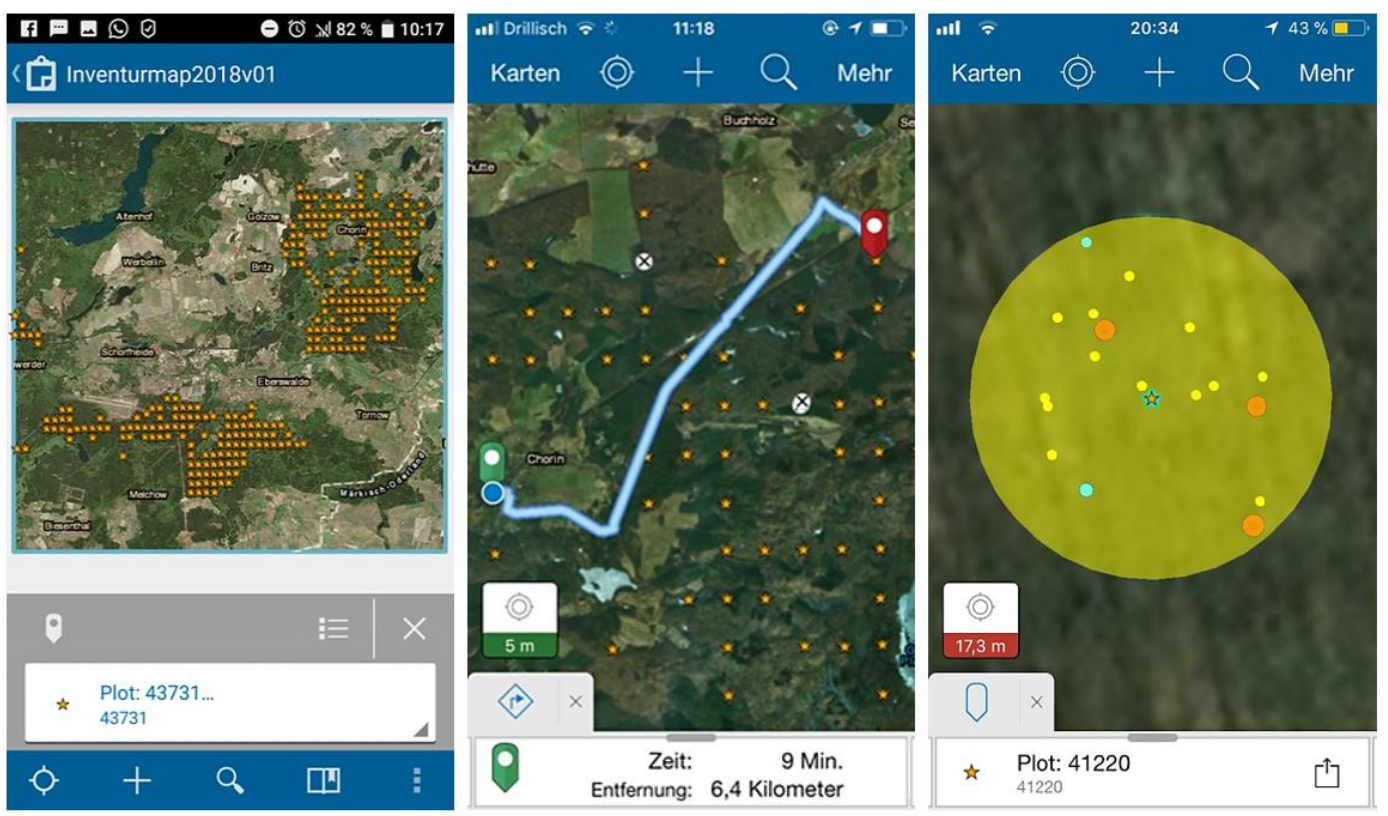

Figure 6: ESRI ArcGIS Online collector app screenshots of student fieldwork.

From left to right: Inventory plot overview map, navigation map, and individual plot map with approximate GNSS assisted real-time geolocation of the handheld computer

Applying mobile geospatial technology and using geo-information software in the field such as LBS in a partially self-organized learning environment, both on- and offline, also requires the manipulation of data through analysis and synthesis of datasets (Trautmann et al., 2010; Hall-Wallace and McAuliffe, 2002).

Since mobile networks still offer only weak to fair coverage and narrow bandwidth in rural or remote areas like forests, an off-line mobile application such as the ArcGIS mobile collector app is essential for supported mobile data collection.

\section{Monitoring and Evaluation}

Learning is decoupled from the lecture hall and put into a work-related context that uses digital media, in order to increase students' motivation and relevance from their future careers. Professional, conceptually methodical and correctly presented results are a strong indicator of students' successful learning. The educational forest inventory datasets produced in the students' fieldwork form part of the evaluation of their learning progress. The degree of digital and methodological innovation in their project work also indicates the students' ability to transfer knowledge and skills.

Reviewing the results obtained over the course of two years, the data and project reports presented reveal that a number of students have benefitted to an exceptional extent from this module (Figures 7 and 8). Their reports and data surpass expectations in terms of display and 
accuracy, and the level of reflection. For most students, the report indicates that their understanding of geospatial information and forest inventory has increased. However, reviewing the results does not pinpoint why understanding increased. Here a gap exists between module design, didactics and indications of learning progress. Other reports with less qualitative results indicate a digital divide among the students. The assumption that LBS and AR would engage the majority did not turn out to be true.

In order to gather empirical evidence, a survey was designed to investigate students' level of content uptake and to identify obstacles to applying digital data collection independently in the field. In 2018, an online questionnaire was sent to participants on six data-collection courses. Questions related to when the students used the mobile data collection app, with what effect, and any benefits for their GIS project work. Despite efforts on our part, the response rate remained low, at $25 \%(n=54)$. The majority of those who responded were second-term students who were under 25 years old. Surprisingly, as their age group can be categorized as digital natives, many stated that they had no previous experience of digital learning and geospatial data. 36\% answered that working with the ArcGIS Collector and AR tools speeded up their work.

Figures 7 and 8 display empirical results of the student survey.

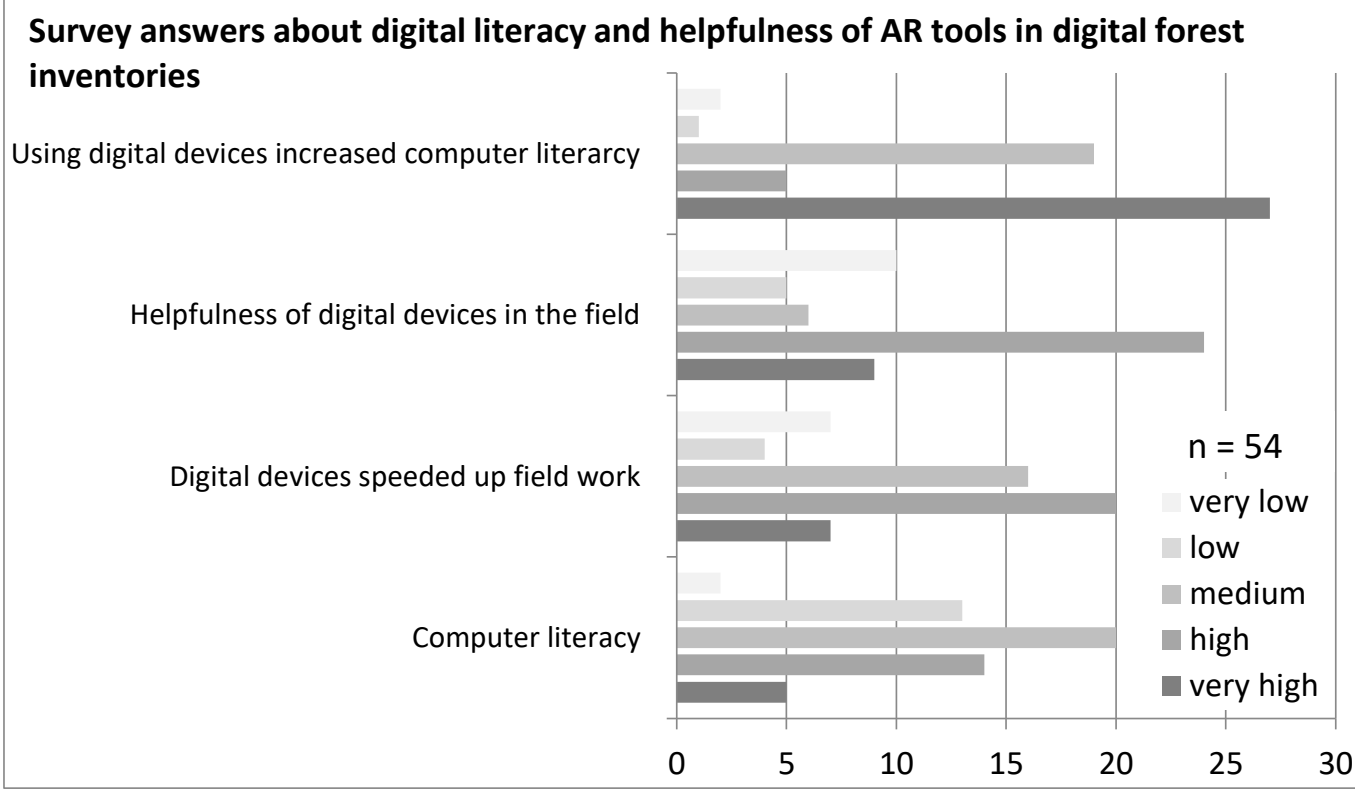

Figure 7: Answers to online student survey in 2019 about computer literacy and helpfulness of AR tools in digital forest inventories 


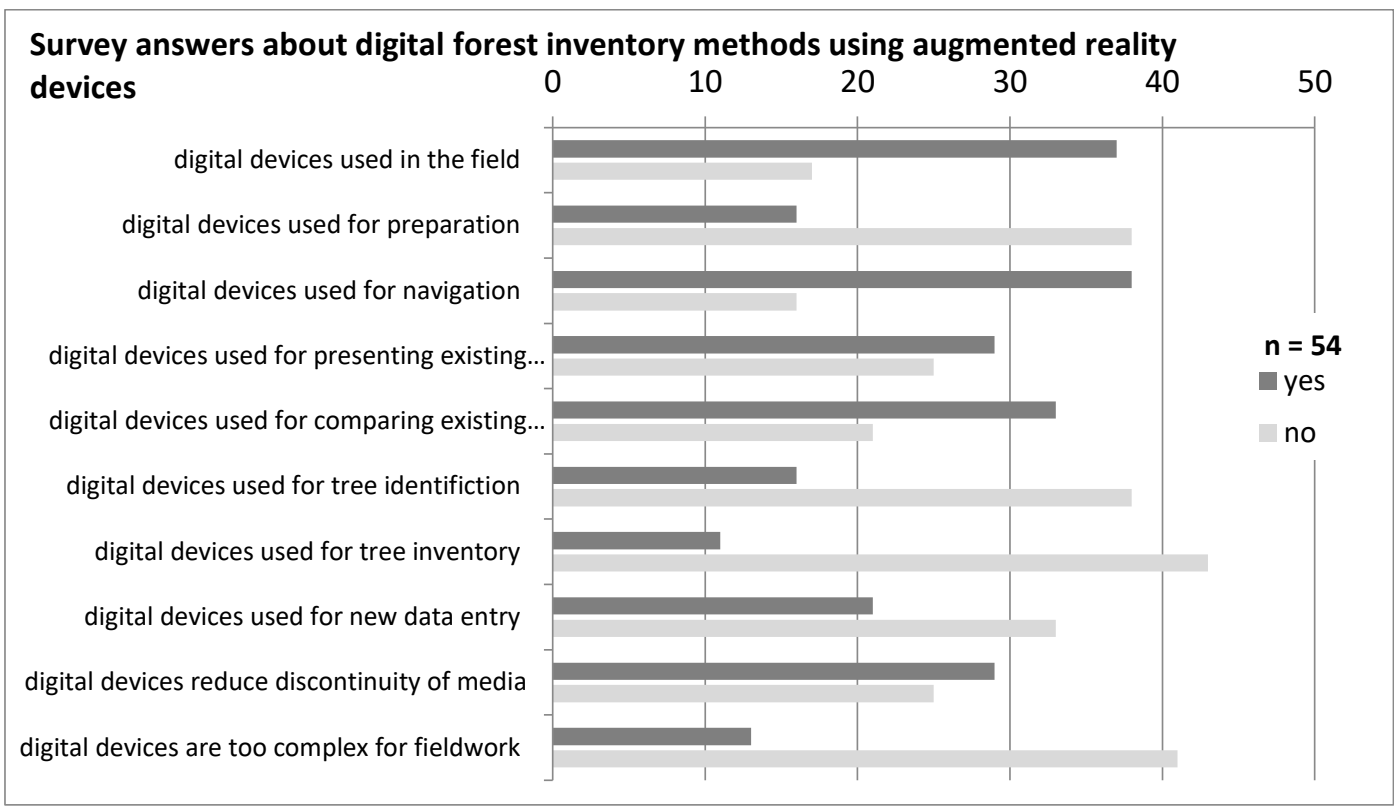

Figure 8: Answers to online student survey in 2019 about digital forest inventory methods using AR devices in 2017-2019.

The integration of the ESRI ArcGIS online Collector app and AR assists students on their particular forest inventory plot by providing previously collected data and other contextual information as 'visual methods of instruction [...] to facilitate schema acquisition by novices', as Howarth and Sinton (2011) summarize. A large majority confirmed this, stating that the ArcGIS Collector App was helpful for their fieldwork assignment.

Asked what obstacles they encountered working with the ArcGIS Collector App, respondents gave four types of reason:

1. External reasons like poor mobile reception, insufficient storage or server crashes.

2. Inadequate content-related understanding, e.g. of the parameters to be collected.

3. App-related reasons, e.g. 'App is insufficient in the terrain', or 'App is not intuitive enough'.

4. Individual reasons: insufficient knowledge to use and understand the software. Others said that they were 'not technophile' or 'computer freaks'.

These statements reinforce the impression of a digital divide among the students (see Figures 7 and 8). Questioned on the comparison of recent and past datasets, respondents criticized the quality of the data collected by previous student groups. This pinpoints good and accurate results and inaccurate results at the same time, which impacts on the quality of the AR. Given the low number of respondents $(n=54)$, the survey results cannot be interpreted as providing representative answers or directions for curriculum re-design. The opinions gathered can only indicate trends, and voices to be taken into account in future revisions. Finally, because of the qualitative limitations of the survey questions, it is not possible to draw any conclusion as to 
whether students' digital literacy improved thanks to the positive learning experiences gained from the innovative method.

In regular university evaluations, many students have stated that self-organized learning structures contribute positively to their learning results and increase their motivation to try out e-learning approaches. Reactions of students during the term indicate that the ongoing flipped classroom approach, the fine-tuned learning progress, and the continuous preparation for the examination projects were well received. However, bias due to lecturer-student interactions cannot be ruled out.

\section{Discussion and Conclusion}

This paper has provided a snapshot of the re-design of a blended learning module that merges topical content with various largely technology-based methods to enhance learning of environmental data collection procedures in a realistic forest inventory context.

Forest inventory and mensuration methods have a strong spatial dimension in stratified plot sampling, geospatial location and attribute data collection of specific forest and ecological parameters (see Figures 1 and 4). GIS is therefore frequently found in forestry curricula (see e.g. Scholz et al., 2018; Arevalo et al., 2010), but a didactical combination of AR and GIScience tools and methods with forest inventory and mensuration techniques is not widely implemented in higher education curricula, although using virtual reality in technical training is becoming more and more popular (Cochrane, 2016), for example as instruction for operating chainsaws, in flight simulations or in medical school training. However, to the best of our knowledge, only a few studies (e.g. Priestnall et al., 2009; Sommerauer \& Müller, 2014 and Antonioli et al., 2014) discuss the use of AR in teaching geo-science or environmental monitoring, or forest inventories specifically, and reason that $\mathrm{AR}$ has not yet become mainstream because its implementation requires specific technical and other conditions. Curtis sums up a number of barriers for the use of geo-spatial technology in school education: 'prohibitive costs; limited availability of hardware and software; inconsistent access to computers; limited availability of pre-processed data; little or no technical support; lack of training, teacher collaboration, and lesson planning time; disproportionate demands on teachers' time; limited instructional support; and lack of pedagogy' (Curtis, 2015, p. 25). Most of these limitations equally apply to the use of AR in any curriculum. The authors agree with Curtis that the introduction of AR and mobile learning tools poses a challenge to universities and their teaching staff.

The implementation process delivered several lessons for the authors. Next to the technical and conceptual design challenges, the biggest structural challenge is to integrate such a complex module successfully into the standard lecture plan of a BSc curriculum, because the implementation of such fine-tuned, multi-level blended learning requires support structures at faculty and university level as well as flexibility from all teachers involved. Further, the switch from analogue to digital methods involved different departments at the university, and coordination between technical support, tutors and lecturers is time-consuming. Shared motivation of all staff to implement the blended learning scenario is needed. A joint kick-off 
workshop or other awareness-raising activities are needed to explain the advantages and demands of the approach as well as the barriers to it.

This blended learning requires strict time management by teachers and students, and challenges students to remain engaged throughout the learning process. At the same time, students who independently choose a different learning pace state the advantages of e-learning materials and self-structured and organized learning environments. The self-organisable learning sequence presented here can be adapted to various student learning-style preferences and learning experiences. Solutions for those students who are lagging behind or who are 'not technophiles' are to intensify support for the group work, or to introduce stronger facilitation of peer-to-peer learning sessions.

The implementation phase identified problems working with the mobile devices. Tablets and software for data collection need more set-up time than paper and pencil. The availability and number of mobile devices are critical to learning outcomes - old devices with little memory or old operating systems hamper data collection. As rugged tablets are relatively expensive and not available everywhere, the principle „,bring you own device' might solve problems in the future. As the innovation cycles of IT gadgets are short, future generations of students will probably not encounter the same problems as the students during the last two years.

An interesting side-effect of this innovation is the continuous re-inventory of data at the same inventory points: this module continually validates and improves the empirical inventory data quality. The errors encountered in the database facilitate a debate around data quality, and in the long run they will serve to improve data quality.

Comprehensive spatial and attribute data processing of forest inventory parameters with geospatial references to discrete inventory points enables students to model and simulate certain forest growth, yield and stand management scenarios. The processing also allows them to use spatial data analysis methods such as geostatistical interpolation. The continuous recollection of data over the years allows change detection analysis at inventory plots, for example as the topic of a research degree.

The integration of several learning approaches enhanced with mobile computing techniques remains a challenging exercise. However, given the relevance to the sector and the future employability of graduates, implementing further improvements to the module will be a worthwhile exercise.

\section{Acknowledgements}

The development and implementation of this module was an intensive, iterative design process supported by Ms. Mirella Zeidler, geospatial data manager at HNEE. Ms. Gnilke, Mr. Lindenberg and Mr. Krause, graduates from the HNEE, supported the development and implementation of the ESRI-online inventory database.

Mr. Kindermann and Dr. Körner from the LFE-LFB provided the original forest inventory plot database and supported the initial data collection.

Piloting the new approach was supported under an Innovative Teaching Fund of the HNEE (ILL 15-18), and by funding from the federal state government of Brandenburg. 


\section{References}

Adams, Anne; FitzGerald, Elizabeth and Priestnall, Gary (2013). Of catwalk technologies and boundary creatures. ACM Transactions on Computer-Human Interaction (TOCHI), 20(3), p.1-16. Retrieved from: http://oro.open.ac.uk/35323/1/TOCHI\%20submission2.pdf. 11.07.2019

Antonioli, M., Blake, C., \& Sparks, K. (2014). Augmented reality applications in education. Journal Of Technology Studies, 40(2), 96-107.

Arevalo, Javier, et al. (2010). Market-relevant competencies for professional foresters in European graduate education, International Forestry Review 12(3).

Balog, A. \& Pribeanu, C. (2010). The role of perceived Enjoyment in the students' acceptance of an augmented reality teaching platform: A structural equation modelling approach. Studies in Informatics and Control, 19(3), 319-330.

Clark, A.M. et al. GIS (2007). Pedagogy, Web-based Learning and Student Achievement. Journal of Geography in Higher Education, Vol. 31, No. 2, 225-239

Cochrane, T. (2016) Mobile VR in Education: From the Fringe to the Mainstream. International Journal of Mobile and Blended Learning 8(4).

Curtis, Mary D. (2015). 'Analyzing the diffusion of geospatial technologies as instructional tools in high school geography education'. PhD dissertation Texas State University, Retrieved from: https://pdfs.semanticscholar.org/b6ee/28fb513ddab88170b3a018d950a94afb18d5.pdf 11.07.2019

De Witt, C.\& Sieber, A. (Eds.) (2013). Mobile Learning. Potenziale, Einsatzszenarien und Perspektiven des Lernens mit mobilen Endgeräten. Wiesbaden: Springer DOI 10.1007/978-3-531-19484-4.

Dunleavy, M. \& Dede, C. (2014). Augmented reality teaching and learning. In: Spector, M., Merrill, D., Elen, J. \& Bishop, M. J. (Eds.), Handbook of research on educational communications and technology (pp. 735745). New York: Springer.

ESRI CANADA (2017). Smart Digital Strategies for Sustainable Forest Management, 2017: https:/ / resources.esri.ca/ann-stories/smart-digital-strategies-for-sustainable-forest-management

Goff, E.E., et al. (2018). Applications of Augmented Reality in Informal Science Learning Sites: a Review. Journal of Science Education and Technology 27: 433. https://doi.org/10.1007/s10956-018-97344.

Goldstein, D. \& Alibrandi, M. (2013). Integrating GIS in the Middle School Curriculum: Impacts on Diverse Students' Standardized Test Scores, Journal of Geography, 112(2). doi: 10.1080/00221341.2012.692703

Hall-Wallace, M. K. \& McAuliffe, C. M. (2002). Design, implementation, and evaluation of GIS-based learning materials in an introductory geoscience course. Journal of Geoscience Education, 50, 5-14.

Howarth, J. T. \& Sinton, D. (2011). Sequencing spatial concepts in problem-based GIS instruction: Procedia Social and Behavioral Sciences 21, 253-259.

Koltay, Tibor (2011). The media and the literacies: media literacy, information literacy, digital literacy. Media, Culture \& Society 33 (2) 211-221. https://DOI: 10.1177/0163443710393382.

Kopp, M.; et al (2016). Entwicklung von 'eDidactics': Ein Fortbildungsprogramm für den Einsatz von Technologien in der Hochschullehre. Springer Wiesbaden 2016. Doi: 10.1007/978-3-658-137380_16.

Kumar, P. et al. (2019). Applications and Challenges of Geospatial Technology. Potential and Future Trends. Springer. DOI: https://doi.org/10.1007/978-3-319-99882-4.

Lambach, D. et.al. (2017). Inverting the large lecture class: active learning in an introductory international relations course. European Political Science16: 553. https://doi.org/10.1057/s41304-0160078-3

MaKinster, J.; Trautmann, N.; Barnett, M.: (2014). Teaching Science and Investigating Environmental Issues with Geospatial Technology, https://doi.org/10.1007/978-90-481-3931-6 
Moallem, M., et.al. (eds). (2019). The Wiley Handbook of Problem Based Learning. John Wiley \& Sons, Inc.https://doi.org/10.1002/9781119173243.ch11

Morgenroth, J.\& Visser, R. (2013). Uptake and barriers to the use of geospatial technologies in forest management. New Zealand Journal of Forestry Science. 43:16. Retrieved from: http://www.nzjforestryscience.com/content/43/1/16 11.07.2019.

Priestnall, Gary et al: (2009. A student-led comparison of techniques for augmenting the field experience. Retrieved from

http:/ / citeseerx.ist.psu.edu/viewdoc/download?doi=10.1.1.372.3026\&rep=rep1\&type=pdf

11.7.2019

Rathmell, L. (2018).). Augmented reality app launches for landscape designers, 2018. Lawn \& landscape Market Leadership. https://www.lawnandlandscape.com/article/1l-032718-augmented-realityApp-for-landscape-design-build-yard/.

Riedel T., Hennig P., Kroiher F., Polley H., et al. (2017). Die dritte Bundeswaldinventur (BWI 2012). Inventur- und Auswertemethoden, $124 \mathrm{~S}$

Rychen, D.S., Salganik, L.H. (2003). A holistic model of competence. In: Rychen \& Salganik (eds) Key competencies for a successful life and a well-functioning society. Göttingen: Hogrefe \& Huber.

Scholz, J. et al. (2018). Digital Technologies for Forest Supply Chain Optimization: Existing Solutions and Future Trends. Environmental Management 62:1108-1133. https://doi.org/10.1007/s00267-0181095-5

Seipold, J. (2013). Mobiles Lernen - Systematik, Theorien und Praxis eines noch jungen Forschungsfeldes. In: De Witt, C.\& Sieber, A. (Eds.).). Mobile Learning. Potenziale, Einsatzszenarien und Perspektiven des Lernens mit mobilen Endgeräten. Wiesbaden: Springer. DOI 10.1007/978-3-531-19484-4. P. 28 -54.

Sommerauer. P. \& Müller, O. (2014). Augmented reality in informal learning environments: A field experiment in a mathematics exhibition. In: Computers \& Education, doi:10.1016/j.compedu.2014.07.013.

Trautmann, N.M. \& MaKinster, J.G. (2010). Flexibly Adaptive Professional Development in Support of Teaching Science with Geospatial Technology. Journal of Science Teacher Education 21: 351-370. https://doi.org/10.1007/s10972-009-9181-4.

Veas, E., Grasset, R., Ferencik, I. et al. (2013). Mobile augmented reality for environmental monitoring Personal and Ubiquitous Computing (2013) 17:1515-1531, https://doi.org/10.1007/s00779-0120597-z. 